\title{
Effect of Single Nostril Transsphenoidal Resection of Pituitary Adenoma under Neuroendoscope on Hospitalization Time and Bleeding Volume in Patients with Pituitary Adenoma
}

\author{
Haipeng Yuan* \\ Changle Hospital of Traditional Chinese Medicine, Weifang 262400, Shandong Province, China \\ *Corresponding author: Haipeng Yuan, 13406627777@163.com \\ Copyright: ( 2022 Author(s). This is an open-access article distributed under the terms of the Creative Commons Attribution License (CC \\ BY 4.0), permitting distribution and reproduction in any medium, provided the original work is cited.
}

\begin{abstract}
Objective: This study mainly discusses the clinical effect of treating pituitary adenoma by using single nostril transsphenoidal resection of pituitary adenoma under neuro-endoscope, and analyzes the influence on hospitalization time and bleeding volume. Methods: A total of 335 patients with pituitary adenoma treated in our hospital from January 2017 to January 2019 were randomly selected for study. The patients were divided into two groups by number table method. 167 patients in the reference group underwent single nostril transsphenoidal resection of pituitary adenoma under microscope. Also, 168 patients in the study group underwent single nostril transsphenoidal resection of pituitary adenoma under neuroendoscope. The hospitalization time and bleeding volume and other surgical treatment effects were observed and compared. Results: There was no significant difference in the levels of prolactin (PRL), adrenocorticotropic hormone (ACTH) and thyroid stimulating hormone (TSH) between the two groups before operation $(\mathrm{P}>0.05)$; After surgical treatment, the levels of PRL, ACTH and TSH in the study group were lower than those in the control group $(\mathrm{P}<0.05)$; In terms of surgical indexes, the operation time and hospital stay in the study group were shorter than those in the reference group, and the amount of surgical bleeding was less than that in the reference group $(\mathrm{P}<0.05)$; The total tumor resection rate in the study group was higher than that in the reference group, and the incidence of complications such as nasal septal defect, cerebrospinal fluid leakage and diabetes insipidus in the study group was lower than that in the reference group $(\mathrm{P}<0.05)$. Conclusion: For pituitary adenoma diseases, using single nostril transsphenoidal resection of pituitary adenoma under neuroendoscope can improve the tumor resection rate, reduce the bleeding volume and shorten postoperative hospitalization time.
\end{abstract}

Keywords: Neuroendoscope; Single nostril transsphenoidal resection of pituitary adenoma; Pituitary adenoma

Online publication: January 19, 2022

\section{Introduction}

Pituitary adenoma is a kind of neurosurgical tumor, which is caused by malignant proliferation of cells of anterior and posterior lobe of pituitary gland as well as the superior wall of craniopharyngeal tube. It has a high incidence rate. Pituitary plays an important role in human body structure, and hormone secretion is closely related to human growth and development. When pituitary is pathologically changing, it will cause organism hormone secretion gradually disorder. This will affect the physiological function of patients. Patients will have symptoms such as headache, visual field defect and diabetes insipidus. They must be treated as soon as possible to reduce the harm caused by tumor diseases to the body. At present, the first 
choice for the clinical treatment of pituitary adenoma is surgery ${ }^{[1]}$. With the rapid progress of neurosurgical technology, endoscope and microscope for the treatment of single nostril transsphenoidal resection of pituitary adenoma is mainly used at this stage, both of which have their own treatment advantages. Based on this, the effect of treating pituitary adenoma by using single nostril transsphenoidal resection of pituitary adenoma under neuro-endoscope was explored.

\section{Materials and methods}

\subsection{Basic materials}

A two-year study was conducted from January 2017 to January 2019. 335 patients with pituitary adenoma treated in our hospital during the study period were taken as research objects. All the research objects were divided into two groups by number table method. One group was the reference group, including 167 cases, the proportion of men and women was 97:70, the age limit was 24-58 years old, the average age was (48.13 $\pm 2.55)$ years old, the course of disease was 3-13 months, and the average course of disease was $(6.13 \pm$ 1.25) months, all of which were prolactinomas; The other group is the study group, including 168 cases, the proportion of men and women is $98: 70$, the age limit is $25-59$ years old, the average age is (48.21 \pm 2.61) years old, the course of disease is $3-12$ months, and the average course of disease is (6.15 \pm 1.24$)$ months, all of which were prolactinomas; There was no significant difference in the above data calculated by statistical software, which was comparable $(\mathrm{P}>0.05)$.

Inclusion criteria of research objects: (1) All patients were diagnosed by clinical CT, MRI and other imaging examinations, which were in line with the disease standard of pituitary adenoma ${ }^{[2]}$; (2) No drug, surgery or radiation treatment has been carried out recently; (3) All patients were informed and signed the study consent form; (4) The study was reviewed and approved by the hospital ethics committee.

Exclusion criteria: (1) Patients with severe mental illness and cognitive disorder; (2) Patients with cardiovascular disease and severe organic etiology; (3) Patients with tumor diseases in other parts; (4) Patients with contraindications of surgical treatment.

\subsection{Method}

The control group took microscope for the treatment of single nostril transsphenoidal resection of pituitary adenoma. The operation position was selected as a supine position, endotracheal intubation general anesthesia was given, and the nasal cavity of the patient was fully cleaned. The right nostril approach was selected, and the sphenoid sinus recess was fully filled with $0.1 \%$ epinephrine. At the same time, the nostrils on the operation side were effectively dilated with the help of dilator; The sphenoid sinus entrance was observed in detail with a microscope, accurate mucosal dissection was performed, and the sellar floor of the sphenoid sinus was cut open. Surgical instruments were used to remove tumor tissue. During the operation, attention should be paid to avoid injury of the sellar septum. After the operation, sponge gelatin was given to stop bleeding and anti-infection treatment.

The study group underwent single nostril transsphenoidal resection of pituitary adenoma under neuroendoscope. The operation position was selected as a supine position, endotracheal intubation general anesthesia was given, and the nasal cavity of the patient was fully cleaned. The right nostril approach was selected, the sphenoid sinus recess was fully filled with $0.1 \%$ epinephrine and the nostrils on the operation side were effectively dilated with the dilator. Then $0^{\circ}$ endoscopy was used to find the sphenoid sinus opening in the patient's recessus sphenoethmoidalis, and the sphenoid sinus was accurately ground and separated with the help of a grinding drill to promote the complete exposure of the sphenoid sinus. After that, $30^{\circ}$ endoscopy was used for detailed observation to identify the tumor tissue and fully remove the tumor tissue and residual parts. After the operation, sponge gelatin was given to stop bleeding and antiinfection treatment. 


\subsection{Observation indexes}

Endocrine hormone levels including prolactin (PRL), adrenocorticotropic hormone (ACTH) and thyroid stimulating hormone (TSH) between the two groups before and after surgical treatment were detected and statistically analyzed. The surgical treatment indexes, including operation time, bleeding volume, hospitalization time and total tumor resection were observed. After surgical treatment, the complications such as nasal septal defect, cerebrospinal fluid leakage and diabetes insipidus were observed.

\subsection{Statistical analysis}

The data was processed and analyzed by SPSS 23.0 , tested by $\mathrm{t}$ and $\mathrm{X}^{2}$, and expressed by $(\mathrm{x} \pm \mathrm{s})(\mathrm{n} / \%)$. If $\mathrm{P}<0.05$, it indicated that there is a difference in statistical data.

\section{Results}

\subsection{Improvement of endocrine hormone level}

The test statistics are shown in Table 1. There was no significant difference in the levels of PRL, ACTH and TSH between the two groups before operation, $\mathrm{P}>0.05$. After surgical treatment, the hormone levels of PRL, ACTH and TSH in the two groups were effectively reduced. Compared with the control group, the hormone levels in the study group decreased more significantly $(\mathrm{P}<0.05)$.

Table 1. Comparison of hormone levels of PRL, ACTH and TSH between the two groups ( $\mathrm{x} \pm \mathrm{s})$

\begin{tabular}{ccccccc}
\hline & \multicolumn{2}{c}{ PRL $(\mathbf{n g} / \mathbf{m L})$} & \multicolumn{2}{c}{ ACTH $(\mathbf{p m o l} / \mathbf{L})$} & \multicolumn{2}{c}{ TSH $(\boldsymbol{\mu U} / \mathbf{m L})$} \\
\cline { 2 - 7 } Group & Before operation & $\begin{array}{c}\text { After } \\
\text { operation }\end{array}$ & $\begin{array}{c}\text { Before } \\
\text { operation }\end{array}$ & After operation & $\begin{array}{c}\text { Before } \\
\text { operation }\end{array}$ & $\begin{array}{c}\text { After } \\
\text { operation }\end{array}$ \\
\hline $\begin{array}{c}\text { Control group } \\
(\mathbf{n}=\mathbf{1 6 7})\end{array}$ & $18.54 \pm 6.55$ & $13.56 \pm 3.74$ & $5.23 \pm 0.43$ & $4.94 \pm 0.38$ & $2.31 \pm 1.05$ & $2.24 \pm 0.95$ \\
$\begin{array}{c}\text { Research } \\
\text { group (n= 168) }\end{array}$ & $18.28 \pm 6.23$ & $11.41 \pm 1.58$ & $5.19 \pm 0.42$ & $4.71 \pm 0.25$ & $2.30 \pm 1.01$ & $2.17 \pm 0.84$ \\
$\mathbf{t}$ & 0.3723 & 6.8607 & 0.8613 & 6.5480 & 0.0888 & 2.1359 \\
$\mathbf{P}$ & 0.7099 & 0.0000 & 0.3897 & 0.0000 & 0.9293 & 0.0334 \\
\hline
\end{tabular}

\subsection{Surgical indicators}

The operation time and hospitalization time of the study group were shorter than that of the reference group, and the bleeding volume was lower than that of the reference group, $\mathrm{P}<0.05$ (Table 2).

Table 2. Observation and comparison of surgical indexes between the two groups $(\mathrm{x} \pm \mathrm{s})$

\begin{tabular}{ccccc}
\hline Group & N (example) & Operation time $(\mathbf{m i n})$ & Bleeding volume $(\mathbf{m l})$ & Hospitalization time (d) \\
\hline Reference group & 167 & $115.17 \pm 17.49$ & $70.25 \pm 9.87$ & $13.42 \pm 1.87$ \\
Research Group & 168 & $92.34 \pm 13.28$ & $50.36 \pm 8.55$ & $8.65 \pm 1.37$ \\
t & & 13.4600 & 19.7173 & 26.6428 \\
P & & 0.0000 & 0.0000 & 0.0000 \\
\hline
\end{tabular}

\subsection{Tumor resection rate}

After surgical treatment, among 167 patients in the reference group, 136 patients had total tumor resection, 31 patients had partial tumor resection, and the total tumor resection rate was $81.43 \%$. Among 168 patients in the study group, 155 patients had total tumors resection and 13 patients had partial tumors resection, and 
the total tumor removal rate was 92.26\%; By contrast, it was obvious that the tumor resection rate in the study group was higher than that in the reference group, $\mathrm{P}<0.05$, and the data difference was significant $\left(\mathrm{X}^{2}=8.6013, \mathrm{P}=0.0033\right)$.

\subsection{Incidence of complications after operation}

Postoperative observation and statistics showed that the incidence of nasal septal defect, cerebrospinal fluid leakage and diabetes insipidus in the study group was lower than that in the reference group $(\mathrm{P}<0.05)$ (Table 3).

Table 3. Incidence of complications $(\mathrm{x} \pm \mathrm{s})$

\begin{tabular}{cccccc}
\hline Group & $\begin{array}{c}\mathbf{N} \\
\text { (example) }\end{array}$ & $\begin{array}{c}\text { Nasal septal } \\
\text { defect }\end{array}$ & $\begin{array}{c}\text { Cerebrospinal fluid } \\
\text { leakage }\end{array}$ & $\begin{array}{c}\text { Diabetes } \\
\text { insipidus }\end{array}$ & $\begin{array}{c}\text { Total incidence } \\
\text { rate }\end{array}$ \\
\hline $\begin{array}{c}\text { Reference } \\
\text { group }\end{array}$ & 167 & $9(5.38)$ & $4(2.39)$ & $8(4.79)$ & $21(12.56)$ \\
$\begin{array}{c}\text { Research } \\
\text { Group }\end{array}$ & 168 & $3(1.78)$ & $0(0.00)$ & $1(0.59)$ & $4(2.37)$ \\
$\mathbf{t}$ & & & & & \\
$\mathbf{P}$ & & 3.9650 & 4.0726 & 5.6378 & 12.6023 \\
& & 0.0464 & 0.0435 & 0.0175 & 0.0003 \\
\hline
\end{tabular}

\section{Discussion}

The pituitary, as an important organ regulating hormone secretion in the human body, plays an extremely important role in the metabolism and secretion of thyroid stimulating hormones and gonadotropin. Once pituitary adenoma is found, it can lead to a series of symptoms such as acromegaly, amenorrhea and infertility. It will bring great influence to daily life and work. If there is no timely treatment, under the development of the disease, it will even endanger the life and health of patients ${ }^{[3]}$.

At this stage, surgery is the first choice for clinical treatment. Pituitary tumor tissue is removed surgically to help patients recover their pituitary physiological function. Pituitary tumor resection through single nostril transsphenoidal resection of pituitary adenoma under microscope is a common minimally invasive operation. This operation has large operation space and high convenience, and can accurately remove tumor tissue, but there are some deficiencies in the operation. When the nasal cavity is opened, the nasal septum may be damaged, the surgical field is narrow, the tumor tissue may remain, the tumor cannot be completely removed, and the risk of postoperative complications is high ${ }^{[4]}$.

In recent years, with the rapid progress of endoscopic technology, single nostril transsphenoidal resection of pituitary adenoma under neuroendoscope has gradually been widely used. This operation is a new minimally invasive operation. During the operation, the nasal septum can be fully used to minimize the damage of nasal mucosa and nasal septum. At the same time, nasal packing is not required after the operation, which can improve the postoperative comfort of patients. At the same time, the endoscope has a high lighting system, clear and broad vision of operation, which can improve the precision of operation, fully remove tumor tissue and improve the effect of surgical treatment ${ }^{[5-8]}$.

In conclusion, single nostril transsphenoidal resection of pituitary adenoma under neuroendoscope is effective in the treatment of pituitary adenomas, can effectively remove tumors and has high safety.

\section{Disclosure statement}

The author declares no conflict of interest. 


\section{References}

[1] Dong W, Yue C, Zhang Y, et al., 2020, Effect of Treating Different Level of Pituitary Adenoma by Using Endonasal Transsphenoidal Surgery under Neuroendoscope and Analysis of Measures to Reduce Postoperative Complication. Clinical Medicine of China, 036(002): 166-170.

[2] Qu Z, Tian J, Hu Y, et al., 2019, Effect of Single Nostril Transsphenoidal Resection of Pituitary Adenoma under Neuroendoscope on Serum IGF-1 Level in Patients with Pituitary Tumor after Operation. Chinese Journal of Integrative Medicine on Cardio-/Cerebrovascular Disease, 17(18): 132134.

[3] Cui Y, Cheng P, Liu Y, et al., 2019, Comparison of Therapeutic Effects of Neuroendoscopic Intracapsular Resection and External Separation in the Treatment of Pituitary Adenomas. Chinese Journal of Clinical Neurosurgery, 24(12): 43-45.

[4] Xu X, Yang Z, Song J, et al., 2020, Therapeutic Effect of Treating Recurrent Nonfunctional Pituitary Adenoma by Using Endonasal Transsphenoidal Surgery under Neuroendoscope and Microscope. Chinese Journal of Contemporary Neurology and Neurosurgery, 20(03): 68-73.

[5] Guo H, 2019, Effect Evaluation of Treating Pituitary Adenoma by Transsphenoidal Endoscopic Pituitary Tumor Resection on Stress Level and Pituitary Function. Woman's Day, 000(021): 43.

[6] Chen R, Liu Y, 2019, Effect Comparison of Resection of Pituitary Adenoma under Microscope and Single Nostril Transsphenoidal Resection of Pituitary Adenoma under Neuroendoscope. Chinese Journal of Practical Medicine, 2019, 046 (022): 75-78.

[7] Yue X, Mo F, Pan B, 2020, Risk Factors and Management of Common Complications after Endonosal Transsphenoidal Resection of Pituitary Adenoma under Neuroendoscope. Journal of Hebei Medical University, 41(04): 121-124.

[8] Chen J, Huo Y, Shan G, et al., 2019, Comparison of Therapeutic Effect of Endonasal Transsphenoidal Neuroendoscopic Surgery and Microscopic Surgery for Pituitary Adenoma. Zhejiang Journal of Traumatic Surgery, 024(005): 984-985. 